\title{
A206 SKEWED X CHROMOSOME INACTIVATION IN RHEUMATOID ARTHRITIS WOMEN
}

Doua F Azzouz, ${ }^{1}$ Onur Emre Onat, ${ }^{2}$ Nathalie Balandraud, ${ }^{1,3}$ Sami B Kanaan, ${ }^{1}$ Jean Roudier, ${ }^{1,3}$ Tayfun Ozcelik, ${ }^{2}$ Nathalie C Lambert' ${ }^{1}$ INSERM UMR639, Marseille, France; ${ }^{2}$ Department of Molecular Biology and Genetics, Bilkent University, Ankara, Turkey; ${ }^{3}$ Rheumatology department, Hôpital La Conception, Marseille, France

10.1136/ard.2010.149021.16

Background and objectives It has long been recognised that women have a greater prevalence of autoimmune diseases. Rheumatoid arthritis (RA) does not escape this rule with a women:men ratio of 3:1.

$\mathrm{X}$ chromosome inactivation (XCI) is a dosage compensation mechanism used by mammals to ensure that XX females and $\mathrm{XY}$ males equalise $\mathrm{X}$ chromosome gene expression. As a consequence, females are a mosaic of two cell lines, one expressing maternal X-linked and the other expressing paternal X-linked genes with a ratio close to 50:50 when XCI is random.

However skewing, defined as a deviation from the 50:50 ratio has been described in females with autoimmune thyroid diseases, scleroderma and juvenile idiopathic arthritis (for review ${ }^{1}$ ). The aim of the current study is to test whether women with RA also have a skewed XCI.

Methods The highly polymorphic CAG repeat on the first exon of the androgen receptor gene was genotyped, as described elsewhere ${ }^{2}$ to determine XCI bias in 84 women with RA and 100 healthy women.

Results A total of 54 patients and 69 controls were informative for androgen receptor polymorphism. Among them 31.5\% of women with RA (17/54) had a skewed XCI ( $\geq 80: 20)$ compared to only $17.4 \%$ of healthy women (12/69). Only extreme skewing was statistically significant with $18.5 \%$ of patients following this pattern and $2.9 \%$ of controls $(p=0.004)$.

Conclusions Our preliminary data indicate that skewed XCI may be a risk factor for the occurrence of RA in women. Further studies need to be done to analyse whether women who have a skewed pattern have less genetic susceptibilities (shared epitope) or less specific autoantibodies (anti-CCP) as their risk factor is X chromosome linked.

\section{REFERENCE}

1. Lambert NC. The price of silence. Arthritis Rheum 2009;60:3164-7.

2. Ozbalkan Z, Bagislar S, Kiraz S, et al. Skewed X chromosome inactivation in blood cells of women with scleroderma. Arthritis Rheum 2005;52:1564-70. 